\title{
Outcomes of nosocomial viral respiratory infections in high-risk neonates
}

Shairbanu Zinna ${ }^{1}$ MB BS MRCPCH, Arthi Lakshmanan ${ }^{1}$ MB BS MRCPCH, Shin Tan ${ }^{2}$ BM BS, Rebecca McClaughry ${ }^{2}$ BA, Martin Clarkson ${ }^{2}$ BSc, Shiu Soo ${ }^{1} \mathrm{PhD}$, FRCPath, Lisa Szatkowski ${ }^{3} \mathrm{PhD}$, Don Sharkey ${ }^{1,2} \mathrm{PhD}, \mathrm{FRCPCH}$

Affiliations: ${ }^{1}$ Nottingham University Hospitals NHS Trust, Nottingham, UK. ${ }^{2}$ Academic Child Health, School of Medicine, University of Nottingham, Nottingham, UK. ${ }^{3}$ Division of Epidemiology and Public Health, School of Medicine, University of Nottingham, Nottingham, UK

Address correspondence to: Dr Don Sharkey, Associate Professor of Neonatal Medicine, Academic Child Health, E floor, East Block, University Hospital, Nottingham, NG7 2UH, UK. Email don.sharkey@nottingham.ac.uk Tel: +44 1158230602

Short title: Nosocomial viral infections in newborns

Funding Source: Dr Don Sharkey is supported by a Senior Clinical Lectureship Award from the Higher Education Funding Council for England. There were no other funding sources for this work.

Financial disclosure: The other authors have no financial relationships relevant to this article to disclose.

Conflicts of interest: The other authors have no potential conflicts of interest to disclose.

\author{
Abbreviations: \\ VRTIs - viral respiratory tract infections \\ BPD - bronchopulmonary dysplasia \\ NICU - neonatal intensive care unit \\ NEC - necrotising enterocolitis \\ CPAP - continuous positive airway pressure \\ Bi-PAP - bi-level positive airway pressure \\ HFOV - high frequency ventilation \\ ECMO - extracorporeal membrane oxygenation \\ RT-PCR - real time polymerase chain reaction \\ RVP - respiratory viral panel \\ NHS - National Health Service
}

\section{What's Known on This Subject}

Viral respiratory tract infections cause severe respiratory morbidity in ex-preterm infants after NICU discharge. They are now recognized to be more prevalent in the NICU but their longterm impact, prior to discharge, during this early period of life is unclear.

\section{What This Study Adds}

This study identifies the adverse impact viral respiratory infections, particularly rhinovirus, have on newborn infants during their initial NICU admission. Identification of the associated significant respiratory morbidity and healthcare costs should focus efforts on reducing these nosocomially acquired infections. 


\section{Contributors' Statements:}

Dr Don Sharkey conceptualized and designed the study, drafted the initial manuscript, and approved the final manuscript as submitted.

Drs Shairbanu Zinna, Arthi Lakshmanan, Shin Tan, Shiu Soo, Lisa Szatkowski and Miss Rebecca McClaughry and Mr Martin Clarkson carried out the data collection, initial analyses, reviewed and revised the manuscript, and approved the final manuscript as submitted.

All authors approved the final manuscript as submitted and agree to be accountable for all aspects of the work. 


\begin{abstract}
Background Neonatal respiratory disease, particularly bronchopulmonary dysplasia, remains one of the leading causes of morbidity and mortality in newborn infants. There is increasing evidence that nosocomially acquired viral respiratory tract infections (VRTIs) are not uncommon in the neonatal intensive care unit but there are few studies on their impact on neonatal respiratory outcomes and the associated healthcare costs. This study aimed to assess the association between nosocomial VRTI and neonatal respiratory disease.
\end{abstract}

Methods A matched case-control study was conducted in two tertiary neonatal intensive care units during a 6 year period in Nottingham, UK. Cases were symptomatic neonatal patients with a confirmed real-time PCR diagnosis of a VRTI. Matched controls (gestation and centre) had never tested positive for a VRTI. Multivariable logistic regression was used to test for associations with key respiratory outcomes.

Results There were 7995 admissions during the study period with 92 cases matched to 183 controls. Baseline characteristics were similar with a median gestation of 29 weeks.

Rhinovirus was found in 74\% of VRTIs. During VRTIs, $51 \%$ of infants needed escalation of respiratory support and cases required significantly more respiratory pressure support overall ( 25 vs. 7 days, $\mathrm{P}<0.001$ ). Cases spent longer in hospital (76 vs. 41 days, $\mathrm{P}<0.001$ ), twice as many required home oxygen (37\%, OR 3.94, 95\% CI 1.92-8.06, $\mathrm{P}<0.001)$ and in-hospital care costs were significantly more $(£ 49,664(\$ 71,861)$ vs. $£ 22,155(\$ 32,057), \mathrm{P}<0.001)$.

Conclusion Nosocomial VRTI in neonatal patients is associated with significant greater respiratory morbidity and healthcare costs. Prevention efforts must be explored. 


\section{INTRODUCTION}

Neonatal bronchopulmonary dysplasia (BDP) is associated with long-term respiratory morbidity, including asthma, chronic obstructive airways disease $\mathrm{e}^{1-3}$, and poor neurodevelopmental outcomes ${ }^{4}$. Despite improvements in the respiratory management of preterm infants, and subsequent increased survival, many countries have not seen reductions in BPD. In the UK, $68 \%$ of extremely preterm survivors born in 2006 had BPD, unchanged from 1995 rates $^{5}$. Current US estimates suggest there are between 5000 and 10000 new cases of BPD annually ${ }^{2}$, with respiratory causes of death are second only to immaturity in extremely preterm infants ${ }^{6}$.

The pathogenesis of BPD is multifactorial with the presence of inflammation and prematurity key factors. The inflammatory changes observed are usually a result of infection, ventilatory trauma and hyperoxia ${ }^{7}$. Few studies have explored the role of viral respiratory tract infection (VRTI) in this process although animal studies have highlighted their potential adverse role ${ }^{7,8}$. Following discharge from the neonatal intensive care unit (NICU), surviving preterm infants with subsequent VRTIs are more likely to develop severe respiratory disease or suffer from recurrent wheeze and asthma ${ }^{9-11}$.

Nosocomial VRTIs are often unrecognised or clinically underdiagnosed in the NICU ${ }^{12,13}$ with up to $52 \%$ of admissions testing positive for viral DNA by $\mathrm{PCR}^{14}$. Therefore, it is plausible that VRTIs acquired during the NICU period could worsen BPD in preterm infants although previous studies have mostly been small observational studies ${ }^{12,13,15-19}$. We aimed to assess the association between nosocomial VRTIs acquired in the NICU and respiratory morbidity up to hospital discharge. 


\section{METHODS}

\section{Study design}

This was a retrospective matched case-control study conducted in two large tertiary NICUs in Nottingham, UK, between July 2007 and July 2013 which included the worldwide influenza A (H1N1) pandemic in 2009/10. This timeframe was chosen as it represented the start of detailed electronic record collection for all NICU patients and the introduction of a PCRbased assay for viral detection rather than the immunofluorescence and culture methods used previously. The NICUs care for all newborn infants in the Nottingham area and those requiring intensive care from surrounding hospitals in the Trent Perinatal Network, covering approximately 26,000 births annually. Both NICUs are part of the same organization (Nottingham University Hospitals NHS Trust) with the same infection prevention and control measures. Infants with VRTIs are barrier nursed in an enclosed incubator until asymptomatic. No re-admissions are allowed once discharged from hospital after their birth. Parents could visit anytime, with siblings and other relatives allowed between $2 \mathrm{pm}$ and $8 \mathrm{pm}$. A restricted visiting policy was in place during the months of November to April in 2009, 2010 and 2011 where only parents could visit as a precautionary measure in view of the H1N1 pandemic. Visitors with respiratory illnesses were advised not to visit until symptom free.

Cases were defined as any infant cared for on the NICU whom the clinical team deemed to have symptoms or signs consistent with a VRTI ${ }^{17}$ and had RT-PCR positive viral DNA in airway secretions. Following resolution of symptoms, infants who became symptomatic again with a new infection were included only if this was more than 14 days beyond the initial positive test and with a different viral agent to reduce the risk of genomic persistence in the airway $^{20}$. Two controls were matched per case according to 1$)$ gestation ( \pm 1 week), 2) centre in which they received the majority of their care and 3) born within 6 months of the case to 
minimise variations in care over time. All infants studied were admitted to the NICU after birth.

Data were collected on a standardised proforma, from both the clinical notes and hospital electronic records. Gestational age was determined by ultrasound scanning or, if this wasn't available, last menstrual period. Clinical data included birth weight, mode of delivery, number of siblings, number of courses of maternal steroids, maternal infections in pregnancy, maternal smoking, intra-uterine growth retardation and surfactant doses. Postnatal data included time in hospital, days of respiratory support and other co-morbidities such as congenital heart disease, retinopathy of prematurity (requiring treatment) and a clinical diagnosis of necrotising enterocolitis (NEC).

For cases, the escalation of respiratory care was defined according to set criteria by at least one step up the support pathway from their immediate pre-infection status: no support $\rightarrow$ oxygen only $\rightarrow$ continuous positive airway pressure $(\mathrm{CPAP}) \rightarrow$ Bi-level positive airway pressure $(\mathrm{BiPAP}) \rightarrow$ invasive ventilation $\rightarrow$ high frequency ventilation $(\mathrm{HFOV})$ or extracorporeal membrane oxygenation (ECMO). BPD was defined as infants $<32$ weeks gestation who require oxygen for $>28$ days and at 36 weeks corrected gestation ${ }^{21}$. Infants' requirements for home oxygen were based on the criteria defined by the British Thoracic Society ${ }^{22}$ using an agreed hospital-wide guideline.

Ethical Approval was given by the University of Nottingham Medical School Ethics Committee, reference LTd10042014. 


\section{Sampling and RT-PCR analysis}

All respiratory samples, either nasopharyngeal and/or lung aspirates if ventilated, were collected at the time of the presumed infection and analysed using the multiplex PCR Respiratory Viral Panel (RVP) assay according to a standard operating procedure in a certified National Health Service (NHS) laboratory (see eTable 1 in supplement). Data were also collected on any other positive microbiological samples found \pm 24 hours of the PCR diagnosis of a VRTI.

\section{In-hospital cost of care}

Costs of care were calculated based on the 2011-12 published tariffs for neonatal care in the UK NHS ${ }^{23}$. Costs for each level of care (intensive, high dependency and special care) were calculated to the point of discharge or death.

\section{Data analysis}

Data were analysed using STATA v12 (Stata Corp, College Station, TX). Continuous data are presented as means and standard deviations or medians and interquartile ranges for parametric and non-parametric data respectively. Conditional logistic regression was used to compare the baseline characteristics of cases and matched controls, and then to compare respiratory outcomes including number of days of ventilation required, need for CPAP and number of days spent in intensive care and high dependency. Univariable and multivariable logistic regression, with a-priori adjustment for gestation and centre, was used to calculate odds ratios (ORs) for the association between several potential risk factors and escalation in respiratory support, and discharge on home oxygen. Potential predictors of respiratory morbidity studied included: sex; birth weight; mode of delivery; antenatal steroids; maternal infection; chorioamnionitis; intrauterine growth restriction; maternal smoking; surfactant; Apgar score; cardiac anomalies 
(including patent ductus arteriosus); and NEC. Variables significant at the $10 \%$ significance level $(\mathrm{p}<0.1)$ in a univariable logistic regression model were included in a multivariable model. Data are summarised using ORs with 95\% confidence intervals (CIs). Analyses were two-sided and considered significant if $\mathrm{P}<0.05$. 


\section{RESULTS}

\section{Baseline characteristics}

During the study period, there were 7995 admissions to the NICUs where the study was conducted (1332/year) with a total of 79,642 bed days. Two hundred and seventy five infants (92 cases and 183 controls) met the inclusion criteria. All cases were matched with two controls with the exception of one infant who only had a single control meeting the inclusion criteria. Cases and controls were evenly matched with a median gestation of 29.4 weeks (IQR 26.9-33.9) for the cases and 29.6 weeks (IQR 26.9-34.0) for the controls and both had similar baseline characteristics (Table 1).

\section{Viral infections}

There were a total of 95 nosocomial VRTIs diagnosed by PCR in 92 symptomatic infants (Table 2). Of these, $84(91 \%)$ were preterm with $56(61 \%) \leq 30$ weeks gestation. This equates to a symptomatic nosocomial VRTI incidence of $3.8 \%$ in infants admitted $\leq 30$ weeks' gestation. The median day of life of infection was 43 days (IQR 25-76). Rhinovirus was the dominant pathogen and was detected in 70 cases (74\%). There were five cases of Influenza A H1N1 pandemic strain with escalation of respiratory support in three of those. There were 3 deaths before discharge in the case group, two infants with H1N1 and one with Rhinovirus. Of note, $9(10 \%)$ of the cases had a diagnosis of gastroschisis. A total of 23 cases had blood cultures taken at the time of clinical deterioration, 9 were positive most for coagulase negative staphylococcus $(\mathrm{n}=6)$.

Of the 95 VRTIs there were a 100 viral pathogens identified. There were more than double the number of Rhinovirus infections in the warmer (April to September, $n=47$ ) compared to 
colder months (October to March, $\mathrm{n}=23$ ). This pattern was reversed for other viruses with 7 and 23 in the warmer and colder months, respectively.

\section{Respiratory support}

Overall, $51 \%(n=47)$ of infants required escalation of respiratory support during a VRTI episode (Figure 1). A greater proportion of infants $<28$ weeks gestation required new respiratory pressure support during the VRTI (48\%) compared to those $\geq 28$ weeks $(20 \%$, $\mathrm{P}<0.01)$. For cases, there were no associations identified with the need for escalation of respiratory support and key patient characteristics (supplement eTable 2).

\section{Outcomes - cases vs. controls}

Cases required significantly more ventilation with a median of 7 days (IQR 2.5-27.5) compared to 2 days (IQR 0-8) for controls $(\mathrm{P}<0.001)$. Similarly, cases had a greater requirement for CPAP at a median of 18 days (IQR 1-37) compared to 5 days (IQR 0-33) for controls $(\mathrm{P}=0.026)$. Cases spent significantly more care days at the level of intensive care and high dependency as well as remaining in hospital for longer (76 days vs. 41 days, $\mathrm{P}<0.001$, Figure 2).

Amongst cases $<32$ weeks gestation, $65 \%(n=40)$ had a diagnosis of BPD at 28 days compared to $52 \%(\mathrm{n}=71)$ of controls $(\mathrm{P}=0.09)$ which remained not significant at 36 corrected weeks (cases $52 \%$ vs controls $39 \%, \mathrm{P}=0.81$ ). Univariable conditional logistic regression did not identify any clinical variables associated with VRTI at the predefined statistical level $(\mathrm{P}<0.1)$ to include in a multivariable model. 


\section{Requirement for home oxygen}

At time of discharge, $37 \%(n=34)$ of cases required home oxygen compared to $17.5 \%(n=32)$ of controls $(\mathrm{P}=0.002)$. Cases were also more mature with a mean gestational age of 28.7 weeks (SD 4.1) compared to controls at 26.8 weeks (SD 1.8) $(\mathrm{P}=0.014)$. According to the univariable analysis (logistic regression adjusted a-priori for gestation and centre of care) clinical factors associated with the requirement for home oxygen $(\mathrm{P}<0.1)$ were: a confirmed VRTI, birth weight, maternal infection, 1 minute Apgar $<7$, delivery room surfactant and a cardiac anomaly. These were included in the multivariable model for home oxygen identifying statistically significant associations with: VRTI (adjusted OR 3.94, 95\% CI 1.928.06, $\mathrm{P}<0.001$ ), maternal infection (adjusted OR 2.4, 95\% CI 1.12.-5.13, $\mathrm{P}=0.024$ ), 1 minute Apgar $<7$ (adjusted OR 2.17, 95\% CI 1.02-4.61, $\mathrm{P}=0.047$ ) and a cardiac anomaly (adjusted OR $2.17,95 \%$ CI $1.06=4.45, \mathrm{P}=0.035)$.

\section{In-hospital cost of care}

The 2011 NHS tariff $\operatorname{costs}^{23}$ for intensive care, high dependency and special care were $£ 997$ (\$1443), £726 (\$1051) and $£ 429$ (\$621) per patient per day, respectively. Individual patient costs for cases were $£ 49,664(\$ 71,861)$ and for controls $£ 22,155(\$ 32,057)(\mathrm{P}<0.001$, Figure 3). The total median cost difference between cases and controls equates to $£ 27,509(\$ 39,804)$ (range $£ 1,994-£ 58,269(\$ 2,886-\$ 84,312)$ ) extra per patient. With less intensive and high dependency care, $45 \%(n=83)$ of controls had care costs $<£ 20,000(\$ 28,939)$ compared to only $12 \%(n=11)$ of cases. 


\section{DISCUSSION}

Until recently, nosocomially acquired VRTIs on the NICU were thought to be uncommon. The present study is the largest to date and demonstrates that VRTIs on the NICU are associated with significant respiratory morbidity, increased requirement for home oxygen, and result in more than double the in-hospital care costs prior to first discharge. Using a rigorous matched case-control methodology, the baseline characteristics of the infants are well balanced supporting our belief of the validity of the results.

Neonatal patients often develop respiratory symptoms during septic episodes and are usually screened for bacterial infection before commencement of antibiotics. Recent studies have highlighted that either parallel screening at the time of sepsis concerns, or routine surveillance monitoring, identify VRTI in 8 to $52 \%$ of infants in the NICU ${ }^{12-14}$. Our study has focused on symptomatic infants with a suspected VRTI and identified the most dominant pathogen was Rhinovirus. Other studies ${ }^{13,14,19}$ have not found this to be the dominant pathogen although many of these were prior to the widespread use of PCR and their methodologies may not reliably identify Rhinovirus. After respiratory syncytial virus (RSV), rhinovirus is a common pathogen and responsible for many community respiratory infections ${ }^{24-26}$ and can cause severe respiratory disease in older children requiring hospitalisation ${ }^{11,27}$. As the dominant pathogen in our cases, rhinovirus was associated with a need for increased respiratory support in half of the infants with many of the premature infants requiring additional pressure support ventilation, similar to other smaller studies ${ }^{12,14,17}$. This results in an increase in the level of care, barrier nursing, and requires additional nursing and medical input to manage. 
Rhinovirus infection was seen throughout the year with many of the other viruses only observed during the colder months in keeping with seasonal trends in the $\mathrm{UK}^{25,28}$. Asymptomatic children and older individuals can have viral DNA present in their airway secretions ${ }^{20,29}$ so parents, siblings, staff and visitors may be unaware of the infection risk they may pose to vulnerable infants. VRTIs are known to cause more severe disease in younger individuals ${ }^{30,31}$ which may be further exacerbated in the preterm NICU population with a reduced trans-placental maternal IgG transfer ${ }^{32}$ and an immature immune system. Traditionally, during periods of deterioration in preterm infants on the NICU, clinical teams evaluate the infant for bacterial infection and commence antibiotics until bacterial cultures are negative or the baby improves clinically. It is possible preterm infants who deteriorate on respiratory support may actually have a VRTI but this is not considered by the attending team as the management is mainly supportive with limited treatment options unlike bacterial infection. Bennett ${ }^{14}$ also found VRTIs in preterm infants on the NICU were associated with worse respiratory outcomes although, like our study, causal effect cannot be ascertained. There is strong evidence of the adverse effects VRTIs have on preterm infants during the first few years of life, but few studies have focused on the preterm infant at risk of BPD. The interruption of normal lung alveolisation caused by prematurity could be further compounded by VRTI inflammation and worsening the long-term lung injury ${ }^{7}$, potentially supporting a causal relationship with VRTIs and respiratory morbidity in our study. This hypothesis is supported by other studies that have demonstrated increased respiratory morbidity in preterm infants associated with early lung infection ${ }^{33}$ and in animal models there is evidence that viral infection, in combination with oxygen supplementation, has an adverse impact on the immune response and potential subsequent lung recovery ${ }^{34}$. It is of interest in the present study cases requiring home oxygen were significantly more mature, by almost 2 weeks, compared to controls requiring home oxygen. The reasons for this are unclear but could reflect a more 
mature immune system mounting a greater inflammatory response to the viral pathogen resulting in more lung injury.

There are few published reports on neonatal nosocomial acquired H1N1 and our study adds to the data available highlighting the significant respiratory disease this strain causes, also evident in other outbreaks ${ }^{35,36}$. Three of the five cases of H1N1 required additional respiratory support with two of the infants dying as a direct result of the infection. Our cases occurred over 2 separate winters despite restricted visiting practices. Future studies could address how best to minimise the risks to this population during global pandemics.

In this study, there were on average 15-16 VRTIs/year, mostly in preterm infants. In 2013, there were 6236 infants born alive between 23 and 30 weeks' gestation in England and Wales $^{37}$. Extrapolating 3.8\% of these infants developing a symptomatic VRTI would equate to 237 infants requiring an average of 35 extra days in hospital or 8295 total days. This equates to the annual bed capacity for a $23 \cot$ NICU. Additional NICU costs for this group would be in the region of $£ 6.5$ million (range $£ 4.7 \mathrm{M}-£ 13.8 \mathrm{M}(\$ 9.4 \mathrm{M}, \$ 6.8 \mathrm{M}-\$ 20 \mathrm{M})$ per year. As a greater proportion of infants go home on oxygen the on-going post-discharge healthcare costs are also likely be significant.

Strategies aimed at reducing nosocomial VRTIs include infected patient isolation cohorts, personal protective equipment use by staff, hand hygiene policies and restricting visitors during periods of high community VRTI prevalence ${ }^{17,38,39}$. Few of these have been studied in a systematic way in the NICU and further high quality studies are required. Furthermore, many of these studies have focused on RSV but our study highlights the importance of 
rhinovirus and the lack of seasonality which should be considered with any prevention measures.

The main limitations of this study include its retrospective nature, although the data were collected prospectively. Additionally, only infants the team felt were symptomatic were screened for VRTI and so the overall incidence may have been greater if asymptomatic infants were also screened. Symptom data were not collected and so the clinical diagnosis used a pragmatic approach rather than a clearly defined definition. This study is based on infants in only two tertiary NICUs and so the generalisability to other centres needs to be established. However, the Nottingham NICUs during the period of study had a relatively low rate of BPD in ventilated infants 24-32 weeks gestation according to the Trent Neonatal Survey ${ }^{40}$ with rates significantly lower than similar units during the period 2010-12, perhaps suggesting the present study may underestimate the impact of VRTI in other centres. More detailed lung function data in infancy and childhood would also provide valuable long-term data on the effects of VRTIs during early lung development.

In conclusion, this large, well matched, case-control study has demonstrated significant respiratory morbidity and resource implications associated with nosocomial VRTIs on the NICU. Rhinovirus was the dominant pathogen and more than $1 / 3$ of the infants required home oxygen. One could hypothesise that nosocomially acquired VRTIs not only contribute to BPD in symptomatic infants but could also play a role in those infants with unrecognised infection. With little change in the incidence of BPD, despite advances in respiratory management, and increasing evidence that many infants have unrecognised VRTI, this is a plausible hypothesis. Large, prospective studies could incorporate surveillance programs to test this hypothesis. Strategies such as restricting visiting could reduce the burden of 
nosocomially acquired VRTIs ${ }^{17}$ especially when the viral community load is high during pandemics. 


\section{REFERENCES}

1. Vom Hove M, Prenzel F, Uhlig HH, Robel-Tillig E. Pulmonary outcome in former preterm, very low birth weight children with bronchopulmonary dysplasia: a case-control follow-up at school age. The Journal of pediatrics. Jan 2014;164(1):40-45 e44.

2. Islam JY, Keller RL, Aschner JL, Hartert TV, Moore PE. Understanding the Shortand Long-Term Respiratory Outcomes of Prematurity and Bronchopulmonary Dysplasia. American journal of respiratory and critical care medicine. Jul 15 2015;192(2):134-156.

3. Fawke J, Lum S, Kirkby J, et al. Lung function and respiratory symptoms at 11 years in children born extremely preterm: the EPICure study. American journal of respiratory and critical care medicine. Jul 15 2010;182(2):237-245.

4. Bohm B, Katz-Salamon M. Cognitive development at 5.5 years of children with chronic lung disease of prematurity. Archives of disease in childhood. Fetal and neonatal edition. Mar 2003;88(2):F101-105.

5. Costeloe KL, Hennessy EM, Haider S, Stacey F, Marlow N, Draper ES. Short term outcomes after extreme preterm birth in England: comparison of two birth cohorts in 1995 and 2006 (the EPICure studies). Bmj. 2012;345:e7976.

6. Patel RM, Kandefer S, Walsh MC, et al. Causes and timing of death in extremely premature infants from 2000 through 2011. The New England journal of medicine. Jan 22 2015;372(4):331-340.

7. Londhe VA, Belperio JA, Keane MP, Burdick MD, Xue YY, Strieter RM. CXCR2/CXCR2 ligand biological axis impairs alveologenesis during dsRNAinduced lung inflammation in mice. Pediatric research. Nov 2005;58(5):919-926.

8. You D, Ripple M, Balakrishna S, et al. Inchoate CD8+ T cell responses in neonatal mice permit influenza-induced persistent pulmonary dysfunction. Journal of immunology. Sep 1 2008;181(5):3486-3494.

9. Greenough A, Alexander J, Boit P, et al. School age outcome of hospitalisation with respiratory syncytial virus infection of prematurely born infants. Thorax. Jun 2009;64(6):490-495.

10. Blanken MO, Rovers MM, Molenaar JM, et al. Respiratory syncytial virus and recurrent wheeze in healthy preterm infants. The New England journal of medicine. May 92013;368(19):1791-1799.

11. Tregoning JS, Schwarze J. Respiratory Viral Infections in Infants: Causes, Clinical Symptoms, Virology, and Immunology. Clinical microbiology reviews. Jan 2010;23(1):74-+.

12. Ronchi A, Michelow IC, Chapin KC, et al. Viral respiratory tract infections in the neonatal intensive care unit: the VIRIoN-I study. The Journal of pediatrics. Oct 2014;165(4):690-696.

13. Smit PM, Pronk SM, Kaandorp JC, et al. RT-PCR detection of respiratory pathogens in newborn children admitted to a neonatal medium care unit. Pediatric research. Mar 2013;73(3):355-361.

14. Bennett NJ, Tabarani CM, Bartholoma NM, et al. Unrecognized viral respiratory tract infections in premature infants during their birth hospitalization: a prospective surveillance study in two neonatal intensive care units. The Journal of pediatrics. Nov 2012;161(5):814-818. 
15. Diniz EM, Vieira RA, Ceccon ME, Ishida MA, Vaz FA. Incidence of respiratory viruses in preterm infants submitted to mechanical ventilation. Revista do Instituto de Medicina Tropical de Sao Paulo. Jan-Feb 2005;47(1):37-44.

16. Halasa NB, Williams JV, Wilson GJ, Walsh WF, Schaffner W, Wright PF. Medical and economic impact of a respiratory syncytial virus outbreak in a neonatal intensive care unit. The Pediatric infectious disease journal. Dec 2005;24(12):1040-1044.

17. Kujari AM, Waris M, Lehtonen $L$, Ruuskanen 0 . Respiratory viral infections are not uncommon in neonatal intensive care units. Acta Paediatr. May 2014;103(5):e225-228.

18. Gonzalez-Carrasco E, Calvo C, Garcia-Garcia ML, et al. [Viral respiratory tract infections in the Neonatal Intensive Care Unit]. Anales de pediatria. Apr 2015;82(4):242-246.

19. Thwaites R, Piercy J. Nosocomial respiratory syncytial virus infection in neonatal units in the United Kingdom. Acta paediatrica. Feb 2004;93(444):23-25.

20. Byington CL, Ampofo K, Stockmann C, et al. Community Surveillance of Respiratory Viruses Among Families in the Utah Better Identification of GermsLongitudinal Viral Epidemiology (BIG-LoVE) Study. Clinical infectious diseases : an official publication of the Infectious Diseases Society of America. Oct 15 2015;61(8):1217-1224.

21. Kinsella JP, Greenough A, Abman SH. Bronchopulmonary dysplasia. Lancet. Apr 29 2006;367(9520):1421-1431.

22. Balfour-Lynn IM, Field DJ, Gringras $P$, et al. BTS guidelines for home oxygen in children. Thorax 2009; ii1-26. Available at: http://www.ncbi.nlm.nih.gov/pubmed/19586968, 64 Suppl 2.

23. Team DoHPbR. Payment by Results Guidance for 2011-12. on-line: National Health Service;2011.

24. Tanner H, Boxall E, Osman H. Respiratory viral infections during the 2009-2010 winter season in Central England, UK: incidence and patterns of multiple virus co-infections. European journal of clinical microbiology \& infectious diseases : official publication of the European Society of Clinical Microbiology. Nov 2012;31(11):3001-3006.

25. Zhao H, Green H, Lackenby A, et al. A new laboratory-based surveillance system (Respiratory DataMart System) for influenza and other respiratory viruses in England: results and experience from 2009 to 2012. Euro surveillance : bulletin Europeen sur les maladies transmissibles = European communicable disease bulletin. 2014;19(3).

26. Goka EA, Vallely PJ, Mutton KJ, Klapper PE. Single, dual and multiple respiratory virus infections and risk of hospitalization and mortality. Epidemiology and infection. Jan 2015;143(1):37-47.

27. Costa LF, Queiroz DA, Lopes da Silveira H, et al. Human rhinovirus and disease severity in children. Pediatrics. Feb 2014;133(2):e312-321.

28. Nickbakhsh S, Thorburn F, B VONW, Mc MJ, Gunson RN, Murcia PR. Extensive multiplex PCR diagnostics reveal new insights into the epidemiology of viral respiratory infections. Epidemiology and infection. Mar 2 2016:1-13.

29. Hayward AC, Fragaszy EB, Bermingham A, et al. Comparative community burden and severity of seasonal and pandemic influenza: results of the Flu Watch cohort study. The Lancet. Respiratory medicine. Jun 2014;2(6):445-454. 
30. Bruning $\mathrm{AH}$, Thomas $\mathrm{XV}$, van der Linden $\mathrm{L}$, et al. Clinical, virological and epidemiological characteristics of rhinovirus infections in early childhood: A comparison between non-hospitalised and hospitalised children. Journal of clinical virology : the official publication of the Pan American Society for Clinical Virology. Dec 2015;73:120-126.

31. Lauinger IL, Bible JM, Halligan EP, et al. Patient characteristics and severity of human rhinovirus infections in children. Journal of clinical virology : the official publication of the Pan American Society for Clinical Virology. Sep 2013;58(1):216220.

32. van den Berg JP, Westerbeek EA, Berbers GA, van Gageldonk PG, van der Klis FR, van Elburg RM. Transplacental transport of IgG antibodies specific for pertussis, diphtheria, tetanus, haemophilus influenzae type $b$, and Neisseria meningitidis serogroup $C$ is lower in preterm compared with term infants. The Pediatric infectious disease journal. Sep 2010;29(9):801-805.

33. Beeton ML, Maxwell NC, Davies PL, et al. Role of pulmonary infection in the development of chronic lung disease of prematurity. The European respiratory journal. Jun 2011;37(6):1424-1430.

34. Reilly EC, Martin KC, Jin GB, Yee M, O'Reilly MA, Lawrence BP. Neonatal hyperoxia leads to persistent alterations in NK responses to influenza A virus infection. American journal of physiology. Lung cellular and molecular physiology. Jan 1 2015;308(1):L76-85.

35. Tsagris V, Nika A, Kyriakou D, et al. Influenza A/H1N1/2009 outbreak in a neonatal intensive care unit. The Journal of hospital infection. May 2012;81(1):3640.

36. Vij NK, Stryker CC, Esper FP, Jacobs MR, Gonzalez BE. Influenza A/H1N1/09-10 infections in a NICU during the 2009-2010 H1N1 pandemic. Pediatrics. Nov 2011;128(5):e1297-1301.

37. Statistics OfN. Gestation-specific infant mortality in England and Wales, 2013 tables. 2015.

38. Jefferson T, Del Mar CB, Dooley L, et al. Physical interventions to interrupt or reduce the spread of respiratory viruses. The Cochrane database of systematic reviews. 2011(7):CD006207.

39. French CE, McKenzie BC, Coope $C$, et al. Risk of nosocomial respiratory syncytial virus infection and effectiveness of control measures to prevent transmission events: a systematic review. Influenza and other respiratory viruses. Jul 2016;10(4):268-290.

40. Boyle EM MB, Field DJ, Oddie S, Draper ES. The Neonatal Survey Report 2014. 2015:18. 


\begin{tabular}{|l|c|c|c|}
\hline \multicolumn{1}{|c|}{ Characteristic } & $\begin{array}{c}\text { Cases n=92 } \\
\mathbf{n ~ ( \% )}\end{array}$ & $\begin{array}{c}\text { Controls n=183 } \\
\mathbf{n}(\%)\end{array}$ & p Value \\
\hline Male sex & $49(53)$ & $113(62)$ & 0.19 \\
\hline $\begin{array}{l}\text { Birth weight: } \\
>2500 \mathrm{~g}\end{array}$ & $14(15)$ & $24(13)$ & 0.72 \\
$\begin{array}{l}1501-2500 \mathrm{~g} \\
1000-1500 \mathrm{~g}\end{array}$ & $18(20)$ & $44(24)$ & \\
$<1000 \mathrm{~g}$ & $28(30)$ & $55(30)$ & \\
\hline Antenatal steroids (full course) & $32(35)$ & $60(33)$ & \\
\hline Chorioamnionitis & $64(70)$ & $127(69)$ & 0.94 \\
\hline IUGR & $19(21)$ & $48(26)$ & 0.27 \\
\hline Maternal smoking & $14(15)$ & $30(16)$ & 0.80 \\
\hline Mode of delivery: & $25(27)$ & $43(23)$ & 0.26 \\
\hline Vaginal & $49(53)$ & $92(50)$ & 0.86 \\
Elective caesarean & $7(8)$ & $17(9)$ & \\
Emergency caesarean & $36(39)$ & $73(40)$ & \\
\hline 5 min Apgar <7 & $12(13)$ & $26(14)$ & 0.66 \\
\hline Cardiac anomaly & $28(30)$ & $48(26)$ & 0.42 \\
Of which PDA only & $4(4)$ & $12(15)$ & \\
\hline Necrotising enterocolitis & $20(22)$ & $36(20)$ & 0.69 \\
\hline Retinopathy of prematurity & $15(16)$ & $20(11)$ & 0.21 \\
\hline Death before discharge & $3(3)$ & $13(7)$ & 0.26 \\
\hline
\end{tabular}

Table 1. Baseline characteristics of study subjects. P values represent conditional logistic regression. IUGR=Intrauterine Growth Retardation, PDA=Patent Ductus Arteriosus 


\begin{tabular}{|l|c|}
\hline Virus & $\mathbf{n}$ \\
\hline Rhinovirus & 65 \\
\hline Rhinovirus and Adenovirus & 1 \\
\hline Rhinovirus and H1N1 & 1 \\
\hline Rhinovirus and Parainfluenza virus type 1 & 1 \\
\hline Rhinovirus and Parainfluenza virus type 3 & 1 \\
\hline Rhinovirus and RSV & 1 \\
\hline Parainfluenza virus type 3 & 6 \\
\hline Respiratory Syncytial Virus (RSV) & 5 \\
\hline Influenza A H1N1 strain & 4 \\
\hline Coronavirus & 3 \\
\hline Parainfluenza virus type 2 & 2 \\
\hline Others (one each of Adenovirus, Influenza A, Influenza B, \\
Metapneumovirus and Parainfluenza virus type 4) & 5 \\
\hline
\end{tabular}

Table 2. PCR respiratory tract viral detection in 92 infants. 
Figure 1. Percentage of cases requiring escalation of respiratory support at the time of VRTI diagnosis grouped according to birth gestation category. $n=95$ episodes of infection.

Figure 2. Median (95\% Cl error bars) days spent at each level of care and total hospital stay for cases (shaded boxes) compared to controls (clear boxes). ${ }^{* * *} \mathrm{P}<0.001$

Figure 3. Median (95\% Cl error bars) cost according to level of care and total hospital stay for cases (shaded boxes) and controls (clear boxes). ${ }^{* * *} \mathrm{P}<0.001$ 